\title{
Automatic Particle-Size Analysis of HTGR Recycle Fuel
}

J. E. Mack

W. H. Pechin 


\section{DISCLAIMER}

This report was prepared as an account of work sponsored by an agency of the United States Government. Neither the United States Government nor any agency Thereof, nor any of their employees, makes any warranty, express or implied, or assumes any legal liability or responsibility for the accuracy, completeness, or usefulness of any information, apparatus, product, or process disclosed, or represents that its use would not infringe privately owned rights. Reference herein to any specific commercial product, process, or service by trade name, trademark, manufacturer, or otherwise does not necessarily constitute or imply its endorsement, recommendation, or favoring by the United States Government or any agency thereof. The views and opinions of authors expressed herein do not necessarily state or reflect those of the United States Government or any agency thereof. 


\section{DISCLAIMER}

Portions of this document may be illegible in electronic image products. Images are produced from the best available original document. 


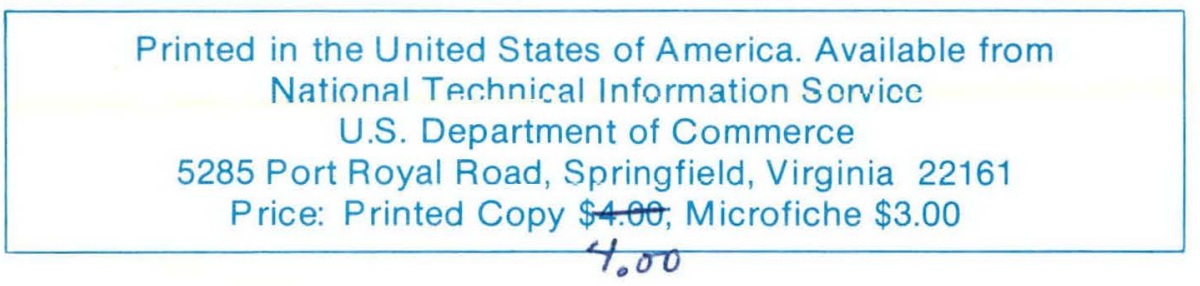

This report was prepared as an account of work sponsored by the United States Government. Neither the United States nor the Energy Research and Development Administration/United States Nuclear Regulatory Commission, nor any of their employees, nor any of their contractors, subcontractors, or their employees, makes any warranty, express or implied, or assumes any legal liability or responsibility for the accuracy, completeness or usefulness of any information, apparatus, product or process disclosed, or represents that its use would not infringe privately owned rights. 
Contract No. W-7405-eng-26

\section{OAK RIDGE NATIONAL LABORATORY GAS-COOLED REACTOR PROGRAMS}

Thorium Utilization Program (189a OH045)

Fuel Refabrication - Task 300

AUTOMATIC PARTICLE-SIZE ANALYSIS OF HTGR RECYCLE FUEL

J. E. Mack and W. H. Pechin

Date Published: September 1977

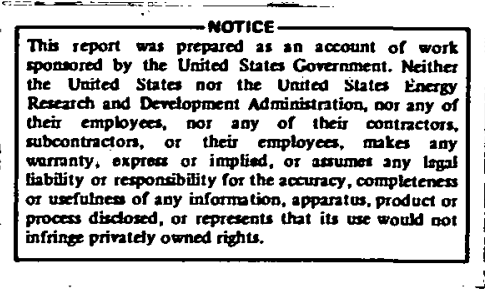

4

OAK RIDGE NATIONAL LABORATORY

Oak Ridge, Tennessee $\mathbf{3 7 8 3 0}$

operated by

Union Carbide Corporation

for the

Energy Research and Development Administration

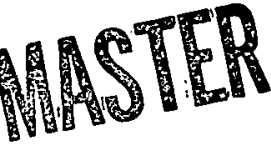




\title{
AUTOMATIC PARTICLE-SIZE ANALYSIS OF HTGR RECYCLE FUEL
}

\author{
J. E. Mack and W. H. Pechin
}

\begin{abstract}
An automatic particle-size analyzer was designed, fabricated, tested, and put into operation measuring and counting HTGR recycle fuel particles. The particle-size analyzer can be used for particles in all stages of fabrication, from the loaded, uncarbonized weak acid resin up to fully-coated Biso or Triso particles. The device handles microspheres in the range of 300 to $1000 \mu \mathrm{m}$ at rates up to 2000 per minute, measuring the diameter of each particle to determine the size distribution of the sample, and simultaneously determining the total number of particles.
\end{abstract}

\section{INTRODUCTION}

The High-Temperature Gas-Cooled Reactor (HTGR) ${ }^{1,2}$ is one of the promising reactor concepts being developed at this time. It offers high thermal efficiency and conserves uranium by using thorium for a portion of its fuel. The high reactor temperatures are possible because graphite is used as both moderator and core structure and because pyrolytic carbon and silicon carbide coatings surround the fuel to retain fission products. The need for metal cladding is thus eliminated. Figure 1 illustrates the two fuel particle types (fissile and fertile) along with the fuel rod and hexagonal graphite core element.

The reactor fuel consists of small spherical uranium oxide-uranium carbide fissile and thorium oxide fertile coated particles. The bare particles or "kernels" are coated with various layers of pyrolytic carbon and silicon carbide. Fissile particles are of the "Triso" design; ${ }^{3}$ they receive three types of coatings, as illustrated in Fig. 2. The fertile particles are of the "Biso" design; they receive only two coatings. Each layer is designed for a specific purpose and must have certain specified properties. The innermost or buffer coating for both Triso and Biso particles is composed of low-density pyrolytic carbon. The buffer provides void space for the accumulation of fission products and serves to shield other layers from damage by fission fragment recoils. The next layer in both the Triso and Biso particle types is known as a low-temperature isotropic layer (LTI): the carbon layer is deposited at a low temperature as compared to certain other processes, and the carbon must be crystallographically isotropic to avoid excessive shrinkage caused by radiation during service. The LTI layer has a higher density than the buffer layer and it acts as a pressure vessel to contain gaseous fission products. This is the last coating applied to the fertile particle and, as is the case with the buffer coating, the layer is considerably thicker in the Biso than in the Triso design. The third coating applied to the fissile particle is composed of high-density silicon carbide which acts as a diffusion barrier to metallic fission products. The fissile particle also has an outer coating of low-temperature isotropic pyrolytic carbon (OLTI) which enhances the bonding which occurs when the fuel particles are formed into rods with a carbonaceous matrix.

1. H. B. Stewart, R. C. Dahlbert, W. V. Goeddel, D. B. Trauger, P. R. Kasten, and A. L. Lotts, "Utilization of the Thorium Cycle in the HTGR," pp. 433-47 in Peaceful Uses of Atomic Energy, Proc. 4th Int. Conf., Geneva, 1971, vol. 4, United Nations, New York and International Atomic Energy Agency, Vienna, 1972.

2. Oak Ridge National Laboratory, Gulf General Atomic, and Idaho Chemical Processing Plant, National HTGR Fuel Recycle Development Program Plan, ORNL-4702, Rev. 1 (Draft, Aug. 11, 1973).

3. W. O. IIarms, "Carbon Coated Carbide Particles for Nuclear Fucls," pp. 290-313 in Modern Ceramics - Some Principles and Concepts, ed. by J. E. Hove and W. C. Riley, Wiley, New York, 1965. 


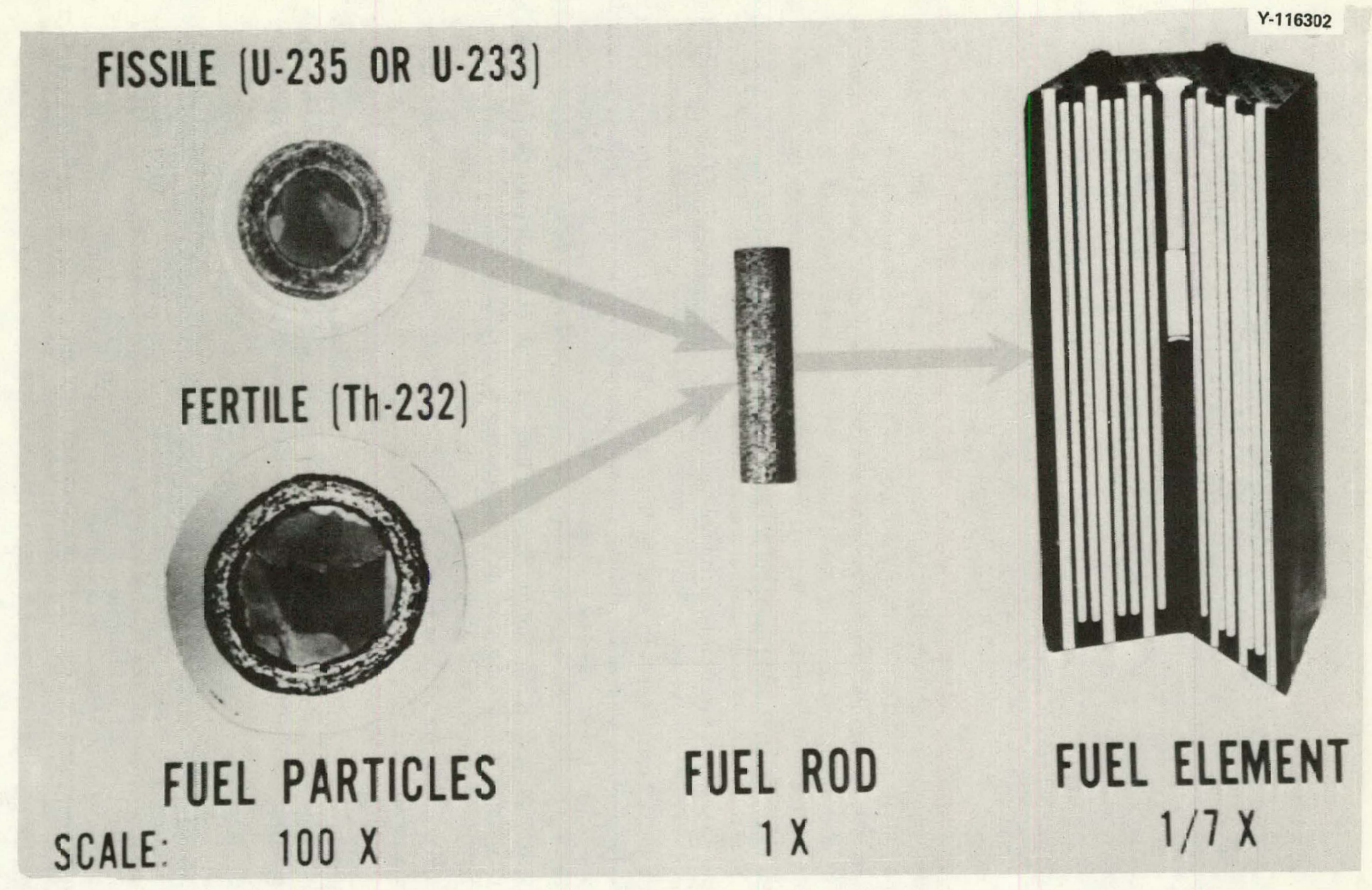

Fig. 1. HTGK. full components. 

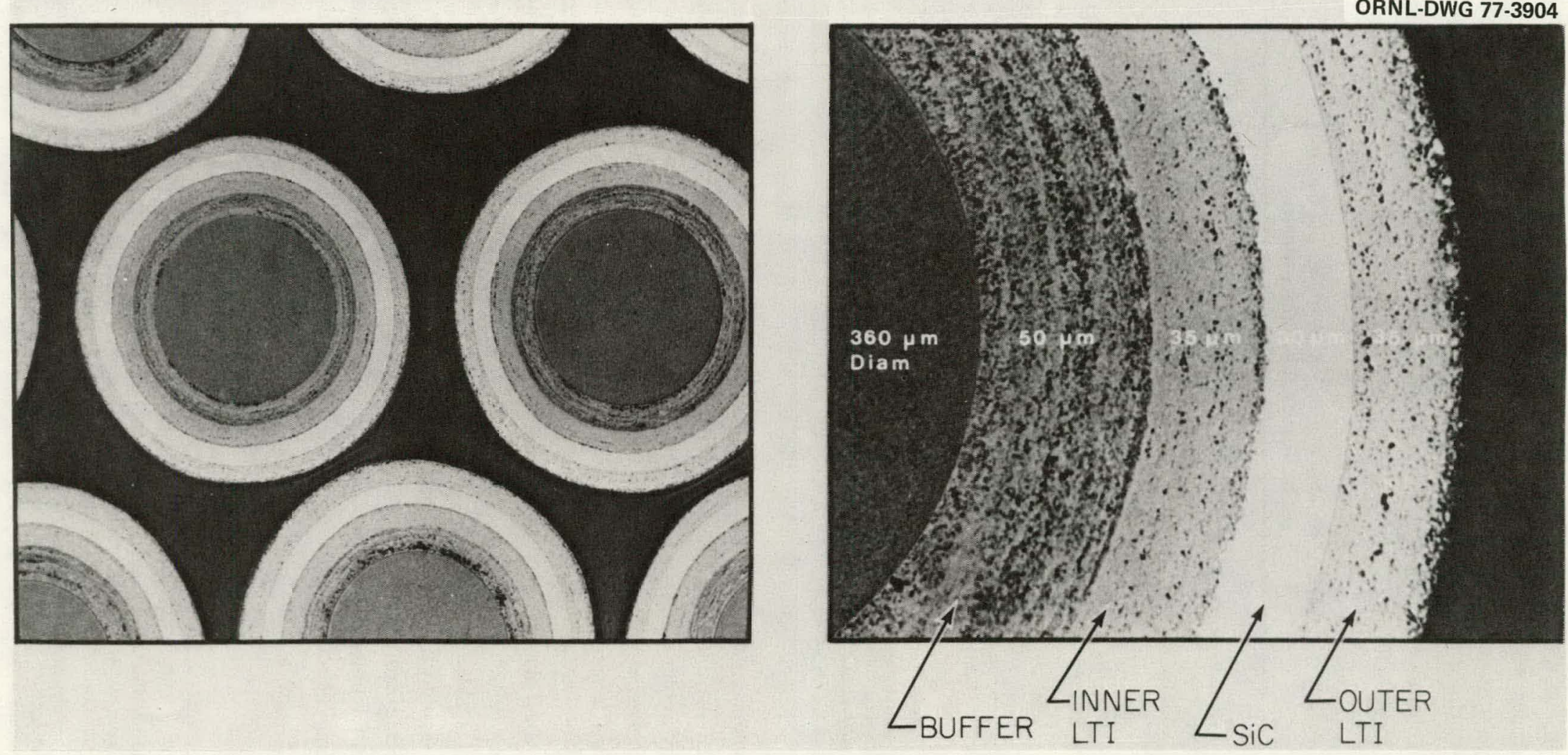

Fig. 2. HTGR "Triso" design fissile fuel particles. 
The dimensions and densities of the kernels and coating layers in HTGR fuel particles are properties of prime interest. Proper performance of the intended function of each coating layer requires that the thickness and density of the applied coating material be within a specified range. ${ }^{4}$ The manner in which the coating is applied results in a variation in coating thickness from particle to particle. ${ }^{5}$ This variation must be determined and controlled during fuel production. The nominal dimensions and densities for the two particle types are listed in Table 1.

Table 1. Nominal dimensions and densities of the Trisoand Biso-coated HTGR fuel particles

\begin{tabular}{lcccc}
\hline & $\begin{array}{c}\text { Coating } \\
\text { thickness } \\
(\mu \mathrm{m})\end{array}$ & $\begin{array}{c}\text { Coating } \\
\text { density } \\
\left(\mathrm{kg} / \mathrm{m}^{3}\right)\end{array}$ & $\begin{array}{c}\text { Particle } \\
\text { diameter } \\
(\mu \mathrm{m})\end{array}$ & $\begin{array}{c}\text { Particle } \\
\text { density } \\
\left(\mathrm{kg} / \mathrm{m}^{3}\right)\end{array}$ \\
\hline & & Fissile (Triso) & & \\
$\mathrm{UO}_{2}-\mathrm{UC}_{2}$ kernel & 50 & $1.1 \times 10^{3}$ & 500 & $3.2 \times 10^{3}$ \\
Buffer & 35 & $1.9 \times 10^{3}$ & 570 & $2.2 \times 10^{3}$ \\
ILTI & 30 & $3.2 \times 10^{3}$ & 630 & $2.4 \times 10^{3}$ \\
$\mathrm{SiC}$ & 35 & $1.9 \times 10^{3}$ & 700 & $2.3 \times 10^{3}$ \\
OLTI & & Fertile (Biso) & & \\
& & & 500 & $10.0 \times 10^{3}$ \\
ThO & & & & \\
Buffer & 85 & $1.1 \times 10^{3}$ & 670 & $4.8 \times 10^{3}$ \\
LTI & 75 & $1.9 \times 10^{3}$ & 820 & $3.5 \times 10^{3}$ \\
\hline
\end{tabular}

Several commercial instruments are available for measuring and/or counting particles; ${ }^{6}$ however, none of the commercial instruments satisfied our criteria. Besides our requirements for size range, precision, and speed of operation, other restrictions were imposed on a measuring device due to the nature of the material in question. The particles are pyrophoric at several stages, requiring inert atmosphere protection to prevent rapid oxidation and degradation. Also, samples containing as little as one-half gram of uranium will require a minimum of $5 \mathrm{~cm}$ of lead shielding to reduce operator exposure to acceptable limits, since the ${ }^{233} \mathrm{U}$ recycle fuel will unavoidably contain trace quantities of ${ }^{232} \mathrm{U}$ along with its associated daughter products. ${ }^{7}$ Accordingly, the particle-size analyzer must be operated and maintained semiremotely within an inert-atmosphere, shielded glove box.

One further restriction is that of sample reclamation. Once the sample has been analyzed and weighed, it must be collected and pneumatically conveyed to other stations for further analyses, such as impurity analysis; analysis for uranium, carbon, and oxygen content; and inspection for damaged particles. As a result, the size analysis must be a nondestructive technique, and damage to the particles must be absolutely minimized.

4. ORNL HTGR Fuel Recycle Development Program, Interim I HTGR Recycle Fuel Product Specifications, Document No. D-11387-TV-A01-0, January 31, 1975.

5. W. J. Lackey, W. H. Pechin, J. D. Sease, Measurement and Control of the Shape of Fuel Particles for High-Temperature Gas-Cooled Reactors, ORNL/TM-4673 (Nov. 1974).

6. R. Davies, "Rapid Response Instrumentation for Particle Size Analysis," American Laboratories, Jan. 1974.

7. J. D. Jenkins, S. R. McNeany, J. E. Rushton, Conceptual Design of the Special Nuclear Material Nondestructive Assay and Accountability System for the HTGR Fuel Refabrication Pilot Plant, pp. 27-58, ORNL/TM-4917 (July 1975). 


\section{RADIOGRAPHIC TECHNIQUE FOR THE MEASUREMENT OF COATING THICKNESS}

One way in which the particle diameter and the thicknesses of the various coatings have been measured in the past is by microscopic examination of an x-radiograph ${ }^{8}$ of the particle sample. This method has been routinely employed since the early stages of microsphere coating development in the HTGR Fuel Refabrication Program. With this method, a batch need not be sampled until the final coating has been applied, since radiography reveals the inner structure of the particle and thus permits thickness measurements to be made on each coating.

The equipment used to read the radiographs is shown in Fig. 3. It consists of a microscope with a filar eyepiece (which is calibrated using a calibration slide), a PDP-8/E (Digital Equipment Corporation) computer to perform the calculations, and a teletype to provide printout. Once the computer is ready to accept data, the operator aligns the hairline in the eyepiece with the outer edge of the particle or at a coating interface, depending on which information is required. The position of the hairline shown on the microcode display is entered into the computer when the operator presses the "read" button.

8. R. W. McClung, Studies in Contact Microradiography, ORNL/TM-3511 (October 1963).

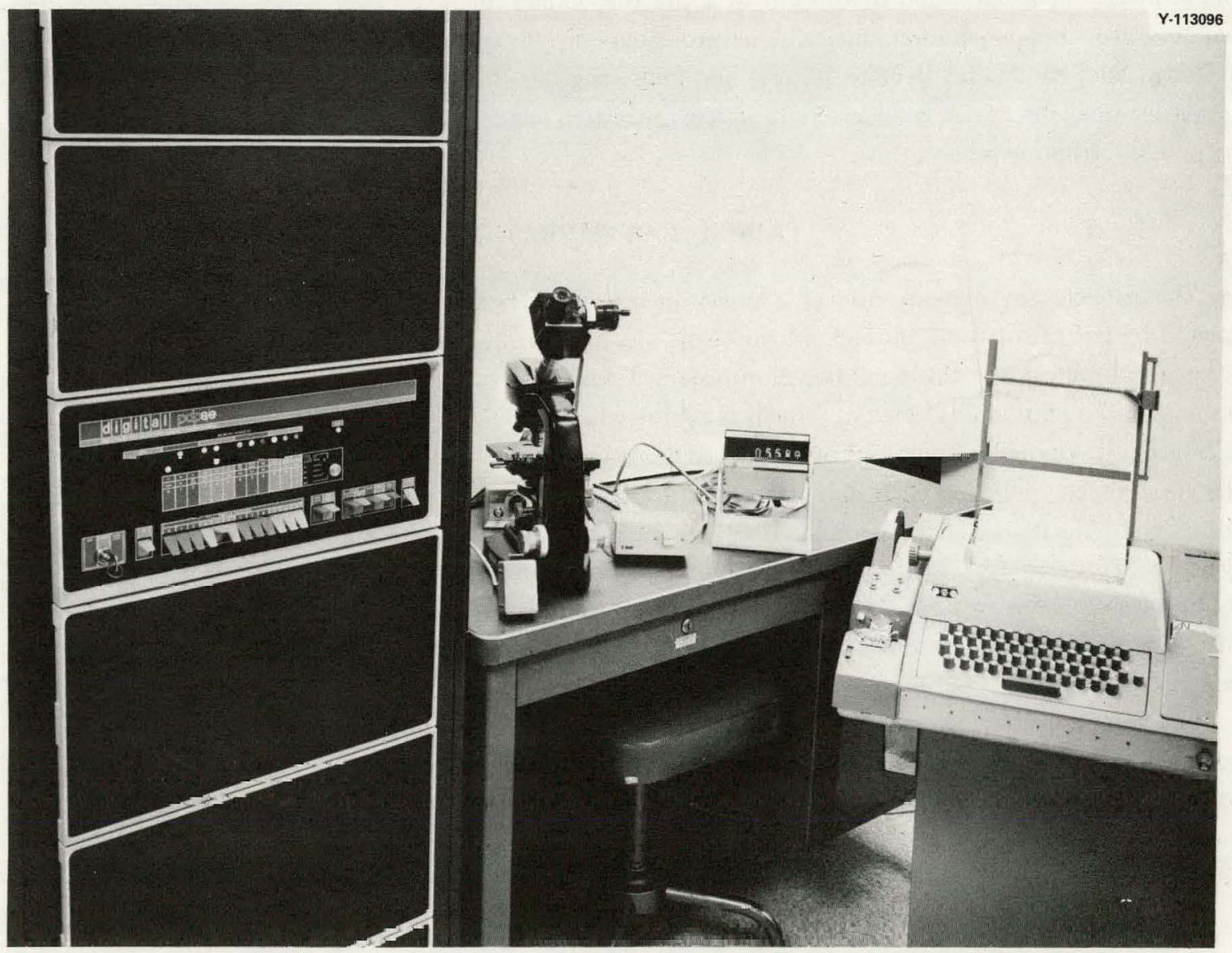

Fig. 3. Equipment used to read particle size and coating thickness from an x-radiograph of the sample. 
As many as ten readings may be taken on a single Triso-coated particle to determine particle and kernel diameters, as well as the thickness of each coating. A shape ratio is obtained from these readings by comparing the coating thickness on one side to that on the other; this provides a measure of sphericity. A spherical particle will have a shape ratio of 1.00 , while a multifaceted particle will have a shape ratio as high as $1.30 .^{9}$ The more faceted a particle is, the greater the number of stress points in the coating and the higher the probability of failure during irradiation. ${ }^{10}$ Rotation of the eyepiece through $360^{\circ}$ permits several diameter and coating thickness measurements to be taken about a single particle, allowing a study of variation in coating thickness within individual particles. Together with the information on particle-toparticle variation, this provides a physical basis for evaluating and modifying the coating process.

The radiograph has a resolution of about $1 \mu \mathrm{m}$, which is adequate. However, to determine the variation from particle to particle and to adequately determine the mean dimension, it is necessary to measure 30 to 50 particles and calculate the mean and standard deviation of the individual measurements. For diameter measurements on 50 particles, the $95 \%$ confidence interval about the mean diameter is typically \pm 3 to 6 $\mu \mathrm{m}$. With manual recording and calculation of the data, this operation requires several hours. Automatic data acquisition reduces the time for measurements and calculations to 15 to $20 \mathrm{~min}$, but the preparation of the radiograph remains a relatively lengthy process, and operator fatigue limits the rate at which radiographs can be read.

In order to eliminate the disadvantages inherent in this technique, an automated particle-size analyzer has been developed. The design of the device is such that it permits rapid measurement of each particle in the sample with a resolution of $0.5 \mu \mathrm{m}$ to $2 \mu \mathrm{m}$ (depending upon the size of the particle) in the time required for the preparation alone of an x-radiograph. In addition, the measurement is performed automatically, eliminating operator fatigue and improving the reliability of the data. Because of the degree of automation, the device is amenable to in-line operation, nondestructively providing quality control data without interrupting process flow.

\section{PRINCIPI.F OF OPERATION}

The particle-size analyzer utllizes a multi-channel pulse height analyzer to measure voltage pulses created by particles passing through a light beam which is directed onto a Schottky photodiode. Figure 4 schematically illustrates this data collection system. The shadow of the particle causes a drop in the current output of the photodiode detector, which is converted to a voltage gain by an amplifier/converter. Since the output of the photodiode is proportional to the amount of light reaching the active surface exposed by the aperture, the pulse height is directly proportional to the shadow cast by the particle and therefore to the cross-sectional area of the particle. The $0.16 \times 0.16 \mathrm{~cm}$ aperture was deliberately chosen to he larger than the particle cross section, thus providing an area measurement rather than a major diameter measurement. The reason for this is that the particles are not perfectly spherical, and the measurement of the cross-sectional area provides a compromise between the diameter and volume, hoth of which are required.

The spacing and velocity of the particles through the light beam must be such as to provide the proper pulse shape for the electronics. The particles must travel through the light beam fast enough to present a rise time short enough to peak within the electronic gate of the analog-to-digital converter $(125 \mu \mathrm{sec})$. They must also pass through the light beam individually, since the appearance of more than one particle shadow on the detector at a given time will result in an error in both particle size and count. To prevent this, the

9. W. L. Lackey, W. H. Pechin, J. D. Sease, Measurement and Control of the Shape of Fuel Particles for High-Temperature Gas-Cooled Reactors, ORNL/TM-4673 (Nov. 1974), p. 5.

10. W. J. Lackey, W. H. Pechin, J. D. Sease, Measurement and Control of the Shape of Fuel Particles for High-Temperature Gas-Cooled Reactors, ORNL/TM-4673 (Nov. 1974), p. 2. 
ORNL-DWG 77-11781

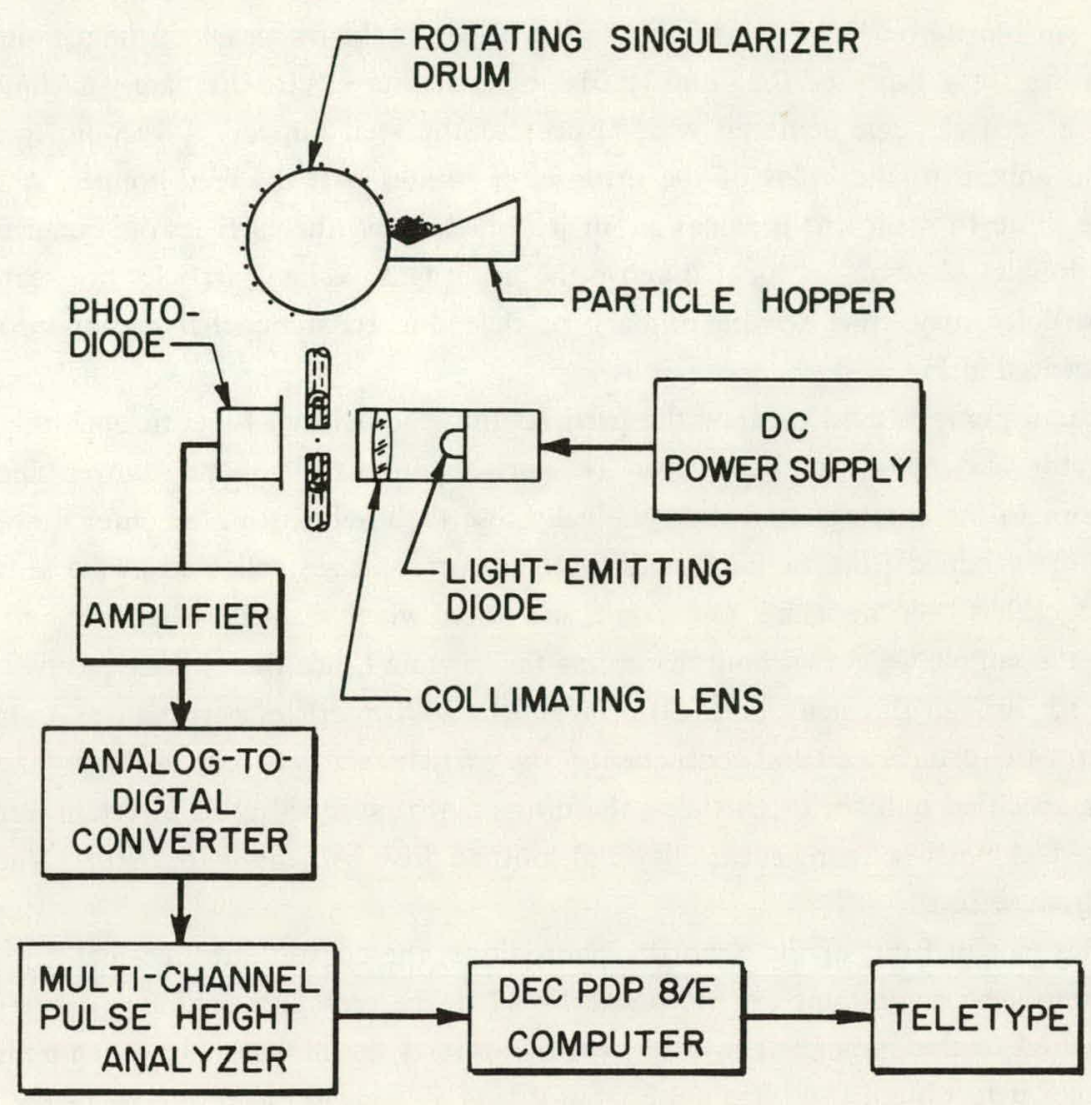

Fig. 4. Electronic particle-size analyzer (information flow diagram).

particles are picked up individually by a rotating singularizer drum, which ensures adequate spacing between particles. Their velocity is determined by the speed of the conveying air which is drawn past the detector and exhausted through a vacuum pump. A cyclone collector is used to disentrain the particles from the air stream.

To eliminate sizing discrepancies caused by different particle trajectories past the detector, the light source must provide a beam of uniform intensity across the field of the sensor. The intensity of the beam must also remain relatively invariant with time. The light source employed is a Fairchild FLV-104 light-emitting diode (LED) with a rated output of $100 \mathrm{mcd}$ operating in the near-red region. The LED is driven by a $6-\mathrm{V}$ regulated dc power supply. Uniformity of the beam is achieved by locating the LED at the focal point of a plano-convex lens, producing a beam of parallel light by essentially focusing the LED at infinity.

The instrument is calibrated with a high-precision (AFBMA Grade 10) calibration sample which consists of stainless steel microspheres of six sizes, ranging from 380 to $800 \mu \mathrm{m}$ with a standard deviation of $\pm 1 \mu \mathrm{m}$ at each size. Periodic checks on calibration are performed with a calibration disk built into the detection module. A separate device permits a single particle to be recirculated through the system to provide data on the precision of the instrument. Each of these techniques is discussed in detail in the following sections. 


\section{INSTRUMENT DESIGN}

The particle-size analyzer is illustrated in Fig. 5. The particle sample is introduced into the singularizer hopper. Particles are transferred from the hopper to the delivery tube by means of the rotating singularizer drum. The drum has forty holes of $0.25-\mathrm{mm}(0.010$-in.) diameter electro-discharge machined around its circumference in a vertical plane centered with respect to the feed hopper. A vacuum inside the drum causes particles to adhere to the holes of the drum as it rotates past the feed hopper. A Teflon nozzle located inside the drum (not shown) provides an air jet which blows the particles off the drum toward the delivery tube. A doublet blow-off jet located above the drum removes any particles not seated in a drum hole, as some particles may cling to the primary particle due to static charge. A photograph of the singularizer is presented in Fig. 6.

A second vacuum pump is used to draw the particles into the delivery tube, through the light beam in front of the detector, and into a cyclone receiver. The particles enter the cyclone receiver tangentially so as to minimize damage to the coatings, and they gradually lose their velocity in the outer slow-speed vortex. The particles are disentrained from the air stream at this point, and are collected in the sample bottle. A rotating vacuum lock has been designed, fabricated, and tested which dispenses the sample to an analytical balance to obtain the sample weight without disrupting the vacuum inside the cyclone receiver.

Particles are fed through the analyzer at rates of 500 to 2000 particles per minute. A stepping motor and indexer control the drum speed and consequently the particle feed rate. Use of the indexer permits the counting out of a specified number of particles; the drum can be stopped after a certain number of steps have been executed. A positive acting gear pulley and toothed drive belt eliminate slippage and increase the precision of the drum setting.

As the particles pass in front of the Schottky photodiode, the current output signal from the detector decreases momentarily by an amount exactly proportional to the cross-sectional area of the particle. The detector output is fed to the amplifier/converter, which converts the milliamp drop to a millivolt gain and amplifies and shapes it to obtain a voltage pulse from 0 to $4 \mathrm{~V}$, depending on the size of the particle. This signal is fed to an analog-to-digital converter which determines the maximum peak height of each pulse by digitizing the pulse when the sign of the derivative changes. This value is then stored as a single count in one of 1024 channels of the multi-channel pulse height analyzer. The channels are linear with respect to voltage, providing a resolution of $\sim 4 \mathrm{mV}$ per channel. Since the particle's cross-sectional area is proportional to the voltage, the area is also linear with respect to channel number, with a resolution of $1000 \mu \mathrm{m}^{2}$ per channel. Particle diameter is not linear but quadratic with respect to channel number, ranging from $2 . \mu \mathrm{m}$ per r.hannel at the low end of the scale to $0.5 \mu \mathrm{m}$ per channel for large particles.

To determine the precision of the instrument, a single particle repeater was designed and fabricated to permit recirculation of a single particle through the particle-size analyzer. The repeater was based on a rotating vacuum lock scheme, consisting of a drum containing six pockets and a Teflnn vacumm seal The. device is attached to the outlet of the cyclone receiver and both are then positioned ahove the singularizer hopper. This arrangement is illustrated in Fig. 7. One or more particles are introduced into the system by being dropped into the singularizer hopper. Each time the particle passes through the analyzer, a measurement is recorded. The particle is then disentrained from the air stream in the cyclone receiver and falls into one of the pockets in the rotating repeater drum. The particle is removed from the vacuum and dropped into the singularizer hopper for the next measurement. This recycling continues until $\sim 200$ counts have been accumulated. Each cycle requires 3 to $5 \mathrm{sec}$ for completion. By running particles of several different sizes simultaneously, an entire spectrum can be accumulated in $15 \mathrm{~min}$.

Using the single particle repeater, steel microspheres of diameter $600 \mu \mathrm{m}$ and larger indicated standard deviations on the order of $\pm 1 \mu \mathrm{m}$ for repeated measurements of the same particle. For steel microspheres of 


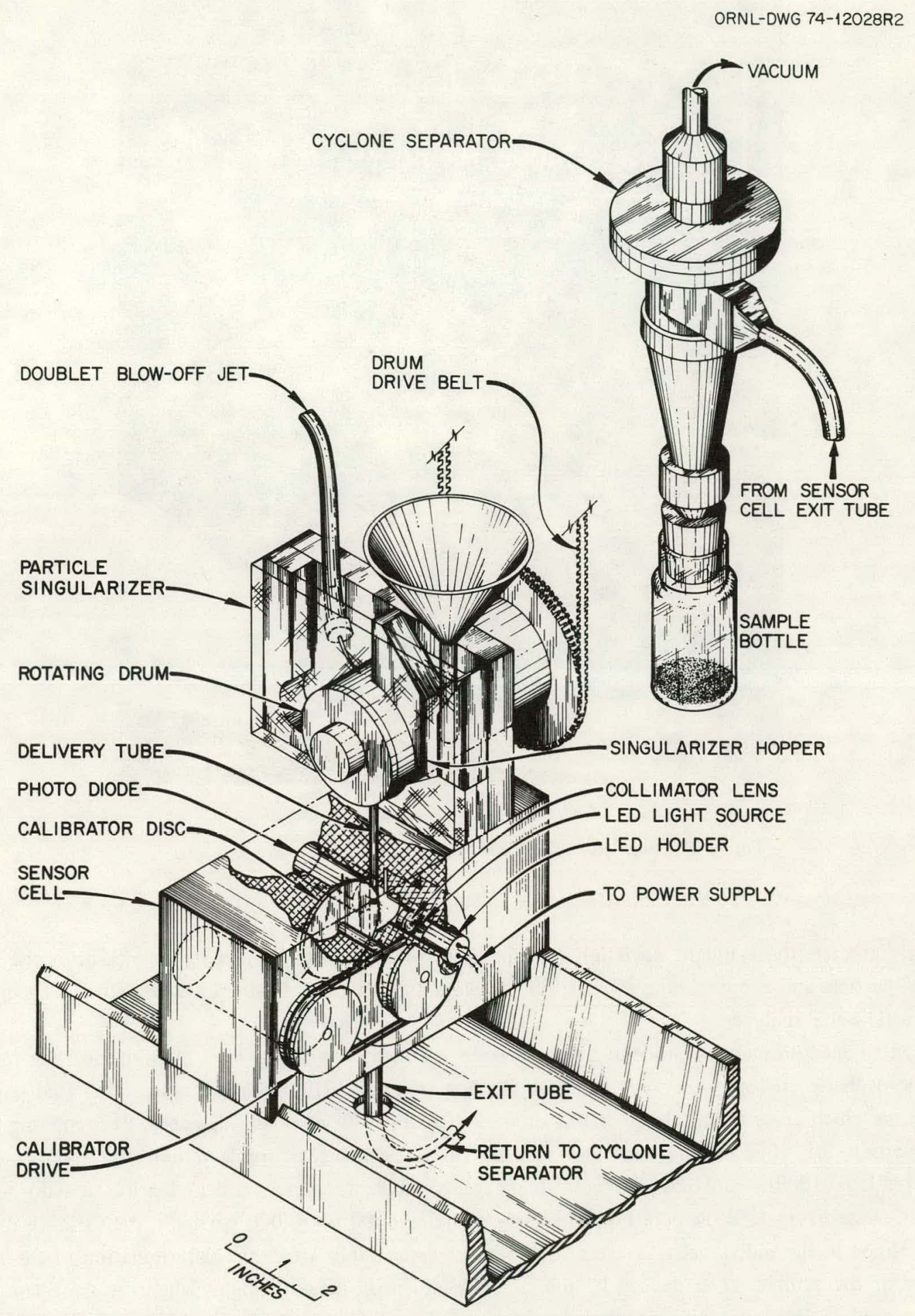

Fig. 5. Particle-size analyzer. 


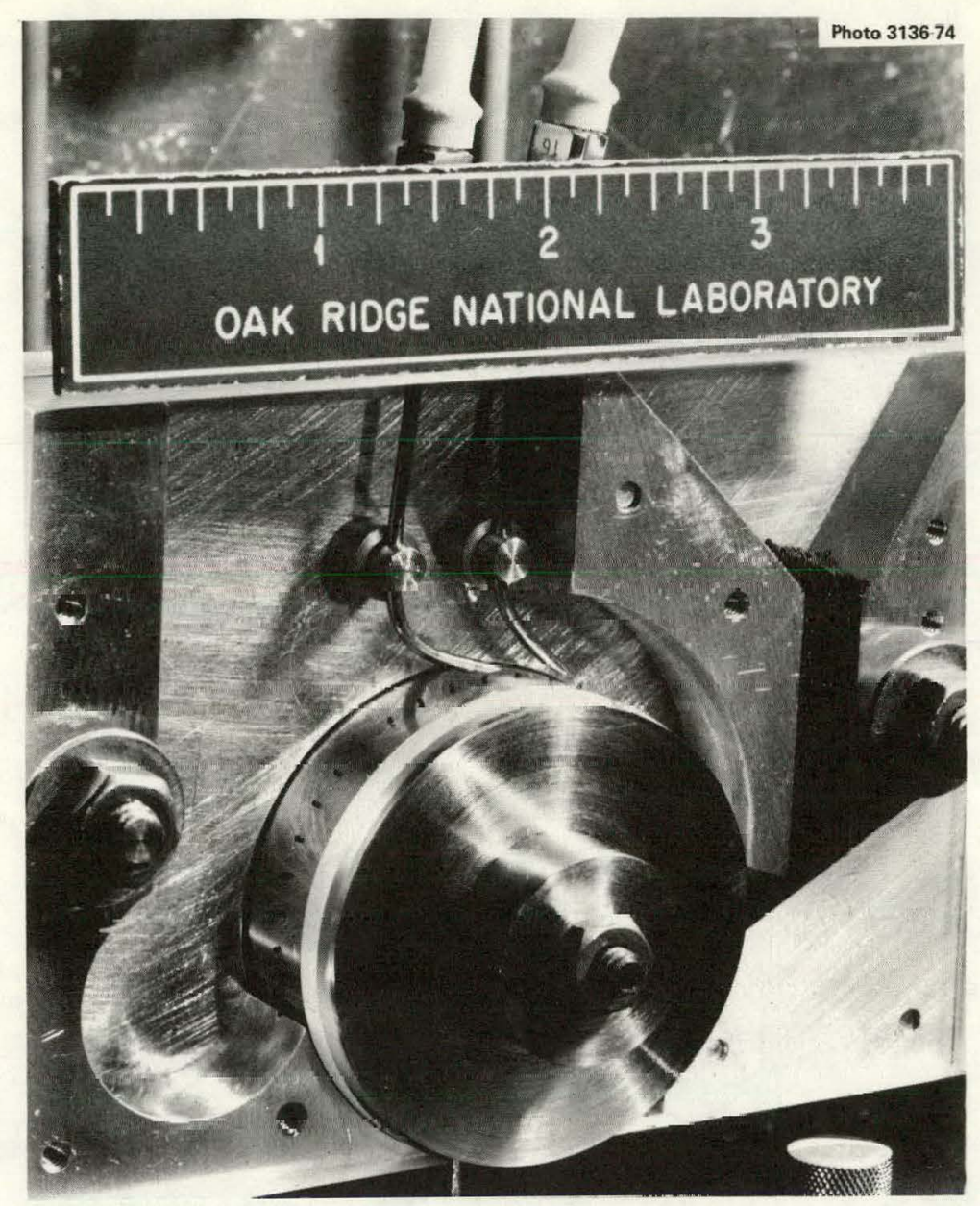

Fig. 6. The singularizer drum and hopper of the particle-size analyzer.

$375 \mu \mathrm{m}$ diameter, the standard deviation was on the order of $\pm 2 \mu \mathrm{m}$. By repeatedly measuring the same spherical particle and accumulating a spectrum, we were ahle to assess the intrinsic precision and accuracy of the particle-size analyzer.

Kepeated measurement of individual fuel particles produces a much broader distribution than for the steel microspheres, because the fuel particles are less spherical. The indicated size of the fuel particle depends on which cross-sectional view it presents as it passes in front of the detector. Recirculating three coated particles of $\sim 650 \mu \mathrm{m}$ diameter produced distributions with standard deviations of $5.2,5.4$, and 7.8 $\mu \mathrm{m}$, increasing with the individual particle shape ratios which had been measured prior to sizing - the largest of these being 1.26. Since a typical sample contains 5000 to 10,000 particles, the variance due to particle shape in the individual measurements does not appreciably affect the determination of the mean diameter of the sample, as evidenced by the close agreement in mean diameter when the same sample is sized repeatedly. Also, since the standard deviations of the samples are typically \pm 20 to $40 \mu \mathrm{m}$ due to the random nature of the coating process, the variance in individual measurements represents only a slight contribution to the overall standard deviation. 


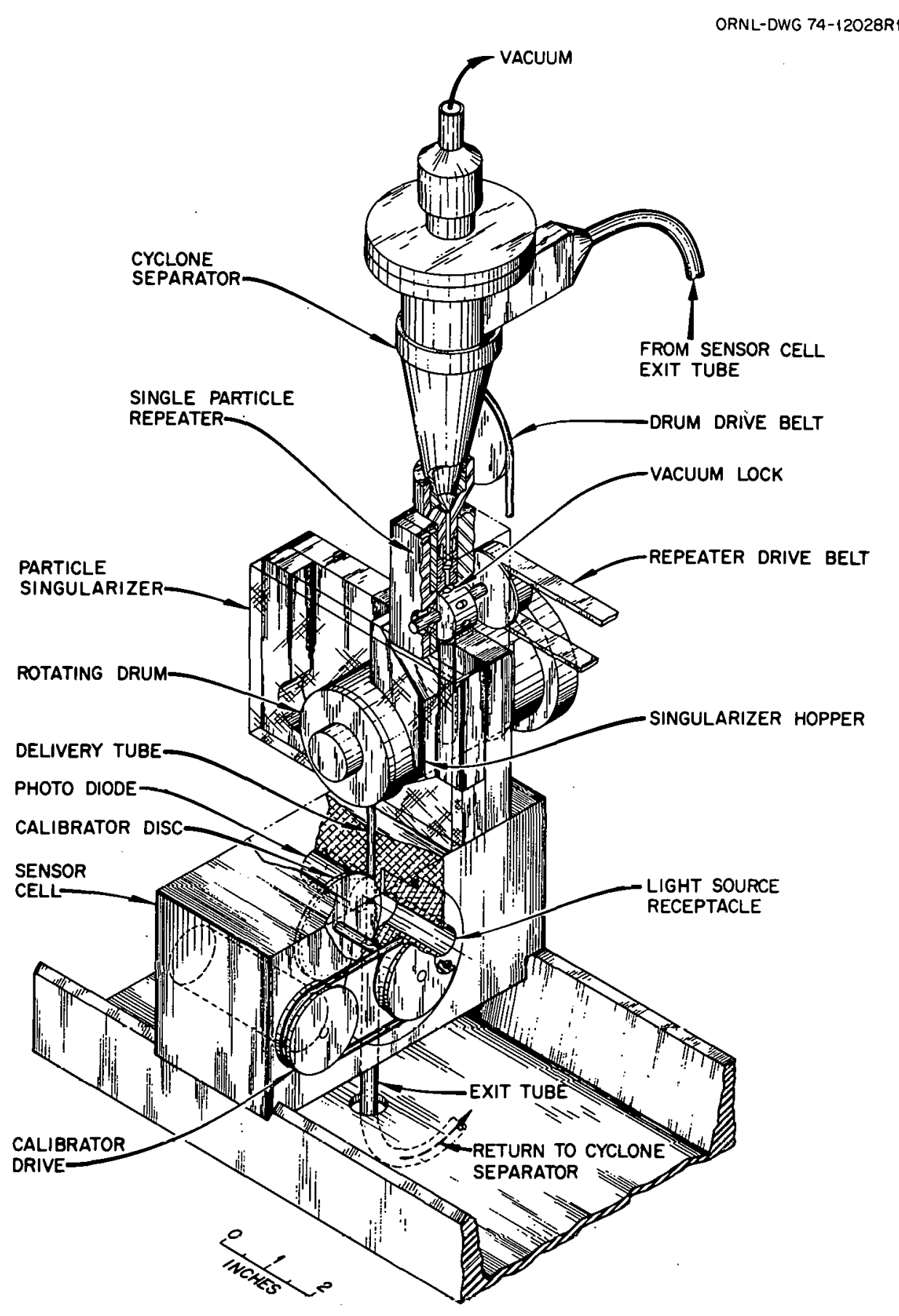

Fig. 7. The particle-size analyzer with single particle repeater. 


\section{INSTRUMENT CALIBRATION}

As mentioned earlier, the magnitude of the voltage pulse created by the particle is directly proportional to the cross-sectional area of the particle. Calibration of the particle-size analyzer is then based on the linear vol tage-to-area relationship $y=m a+b$, where $y$ is the channel number registering the count, $a$ is the cross-sectional area of the particle, and $m$ and $b$ are constants which must be determined. The primary calibration standard for the analyzer consists of a set of high-precision stainless steel microspheres of four sizes, ranging from 380 to $800 \mu \mathrm{m}$, with 200 to 300 microspheres per size. Within each size range there is a size variation of $\pm 1.25 \mu \mathrm{m}( \pm 0.000050 \mathrm{in}$.) as provided by the manufacturer.

The calibration sample produces four distinct peaks across the spectrum of the analyzer. The mean channel of each distribution is calculated according to the formula:

$$
I_{N}=\frac{\sum_{i=j}^{j+n} i \cdot C_{i}}{C_{N}}
$$

where $I_{N}$ is the mean channel of the Nth distribution which registers counts in $n$ channels beginning in channel $j . C_{i}$ is the number of counts registering in channel $i$, while $C_{N}$ is the total number of counts in the Nth distribution.

Accordingly, four mean channels are calculated and stored in the memory of the computer. The cross-sectional area of each of the four sizes of microspheres is calculated, based on the known diameters, and a least squares fit is performed to determine the slope $m$ (in channels $/ \mu \mathrm{m}^{2}$ ) and the intercept $b$ (in terms of channels) of the calibration equation. Fig. 8 illustrates the relationship between cross-sectional areas, diameter, and channel number based upon this calibration. The $m$ and $b$ values are then stored for
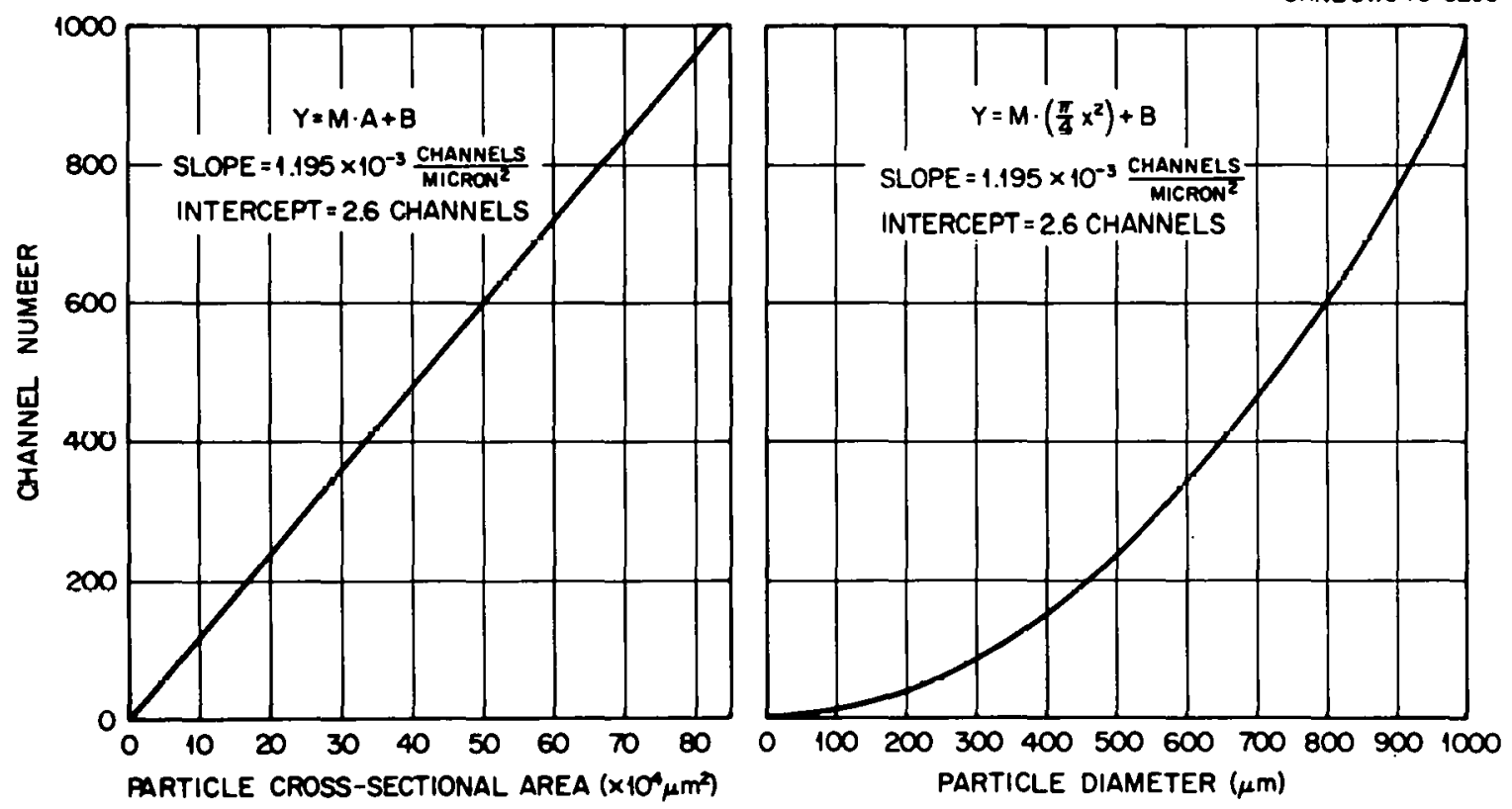

Fig. 8. Calibration curve based on the steel microsphere calibration set; plotting channel number as a-function of cross-sectional area and of particle diameter. 
later use with sample runs. This procedure, which requires $\sim 5 \mathrm{~min}$ to complete, is performed as indicated by the secondary calibration technique described below.

Immediately following the primary calibration, a calibration disk contained within the detection module is rotated at $6000 \mathrm{rpm}$ for $10 \mathrm{sec}$ and a spectrum is accumulated. The disk consists of a plexiglass hub to which six wires are attached radially at $60^{\circ}$ intervals. The wires protrude into the light beam in front of the photodiode while the disk is spinning, as illustrated in Fig. 9, creating pulses similar to those of the particles. The "effective spherical diameter" of each wire is then determined according to the location of its mean channel on the primary calibration curve.

The disk is run prior to each sample as a secondary standard to ensure the validity of the calibration curve. Any drift caused by slight alteration in alignment or intensity of the light-emitting diode, changes in temperature, or aging of the electronic components is detected by changes in the "effective spherical diameters" of the wires. If the indicated diameter of the largest-sized wire $(\sim 1000 \mu \mathrm{m})$ varies by more than $0.5 \mu \mathrm{m}$ from the expected value, the analyzer is recalibrated using the effective diameters determined at the time of primary calibration and the current mean channels. Subsequent particle samples are then measured according to this secondary calibration curve. Should the indicated diameter of the largest-sized wire vary by more than $2 \mu \mathrm{m}$ from its value at primary calibration, the instrument is recalibrated with the primary calibration set.

Once the mean channel of a particle sample distribution has been determined, the variance of the distribution is then calculated according to the relationship:

$$
\sigma_{N}^{2}=\frac{\sum_{i=j}^{j+n}\left(I_{N}-i\right)^{2} C_{i}}{C_{N}}
$$

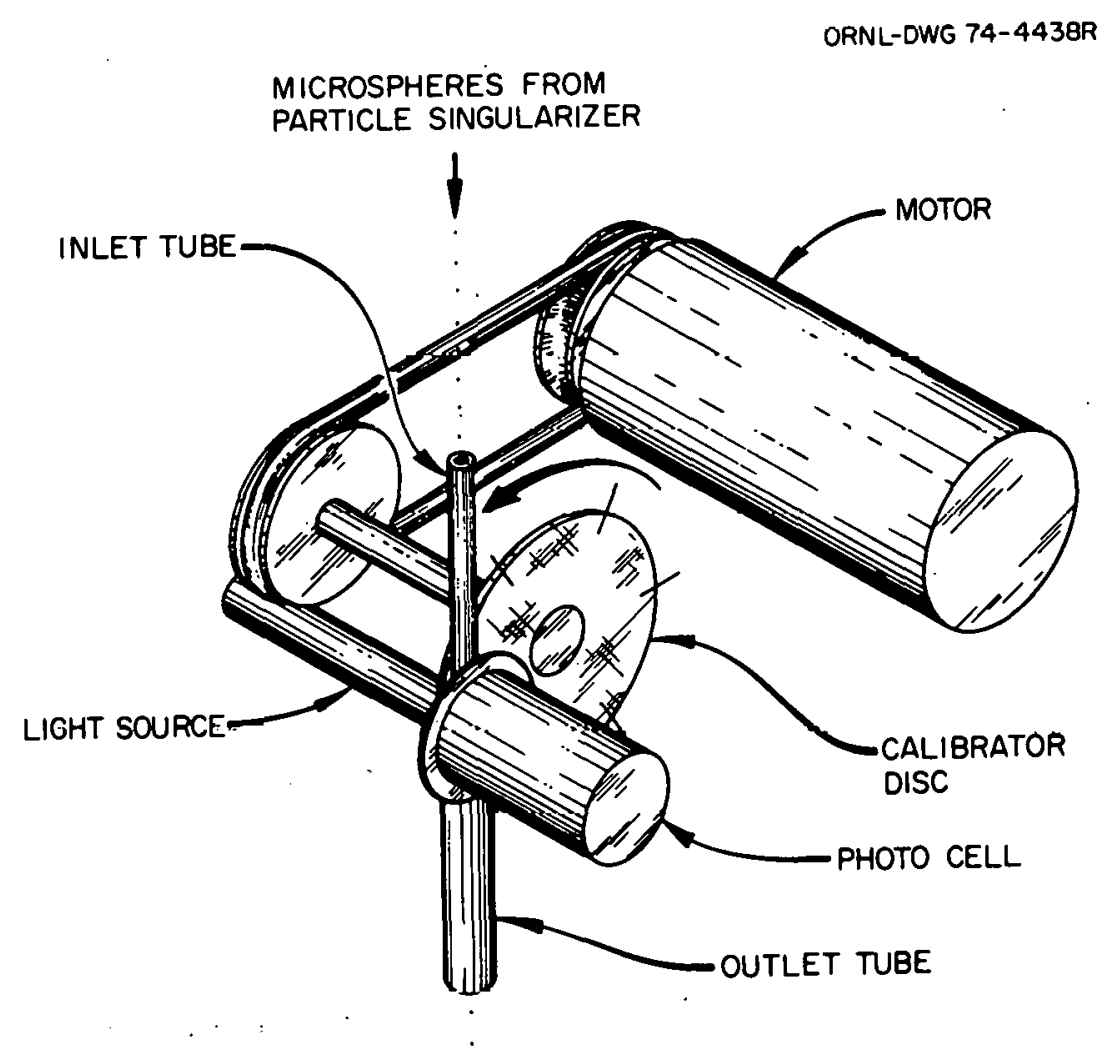

Fig. 9. The wire disc as a secondary calibration standard for the particle-size analyzer. 
where $\sigma_{N}$ is the standard deviation of the Nth distribution in terms of channels, the variance being the square of the standard deviation. The standard deviation of the area measurements, $\sigma_{a}$, is given by $\sigma_{N} / m$, where $m$ is the slope of the calibration curve. The standard deviation of the diameter measurements, $\sigma_{d}$, can be calculated from the relation:

$$
\frac{\sigma_{a}}{a}=\frac{2 \sigma_{d}}{d}
$$

where $a$ is the mean particle area and $d$ is its corresponding diameter. This value of $\sigma_{d}$ is a measure of the sample spread.

It should be noted here that while $d$ is easily calculated, it is not, strictly speaking, the mean particle diameter. The mean area, $\bar{A}$, of a given normal distribution of diamcters is given hy: ${ }^{11}$

$$
\bar{A}=\frac{\pi}{4}\left(\bar{D}^{2}+\sigma_{D}{ }^{2}\right),
$$

where $\bar{D}$ is the mean diameter and $\sigma_{D}{ }^{2}$ is the variance of the particle diameter distribution. In a similar manner, the mean volume is given by:

$$
\bar{V}=\frac{\pi}{6}\left(\bar{D}^{3}+\sigma_{D}^{2} \cdot \widetilde{D}\right)
$$

For a normal diameter distribution, the area and volume distributions will be skewed to the left, the amount of skewness depending on the variance of the diameter distribution.

By calculating a diameter from the mean area, we are essentially taking the "middle" value, minimizing errors in using this value in coating thickness or volume calculations. This approach is taken solely because of current computer programming limitations. The errors introduced in making such a measurement are given in terms of the diameter and variance as follows:

$$
\bar{A}=\frac{\pi}{4} \widetilde{D}^{2},
$$

where $\widetilde{D}$ is the diameter corresponding to the mean area.

Then

$$
\begin{aligned}
& \bar{D}=\sqrt{\bar{D}^{2}-\sigma_{D}{ }^{2}} \\
& \frac{\bar{D}}{\dot{D}}=\sqrt{\frac{\widetilde{D}^{2}-\sigma_{n}^{2}}{\widetilde{D}^{2}}}
\end{aligned}
$$

and

$$
\frac{\bar{D}}{\widetilde{D}}=\sqrt{1-\frac{\sigma_{\mathrm{D}}{ }^{2}}{\widetilde{\mathrm{D}}^{2}}} .
$$

11. Personal communication, C. K. Bayne, Mathematics Research Dept., UCC-ND (Y-12), December 1976. 
Also,

$$
\widetilde{V}=\frac{\pi}{6} \widetilde{D}^{3}
$$

and

$$
\widetilde{V}=\frac{\pi}{6}\left(D^{2}+\sigma_{D}{ }^{2}\right)^{3 / 2} .
$$

Then

$$
\frac{\bar{V}}{\widetilde{V}}=\frac{\left(\bar{D}^{3}+3 \sigma_{D}^{2} \bar{D}\right)}{\left(\widetilde{D}^{2}+\sigma_{D}{ }^{2}\right)^{3 / 2}} .
$$

The calculated diameter is slightly larger than the true mean, while the calculated volume is slightly lower.

For most particle samples, $\sigma_{D}$ varies between 20 and $40 \mu \mathrm{m}$, while particle diameters range from 400 to $850 \mu \mathrm{m}$. For a typical sample with a particle diameter of $600 \mu \mathrm{m}$ and a standard deviation of $30 \mu \mathrm{m}$, the diameter ratio from Eq. 9 is $99.875 \%$, while the volume decrease from Eq. 12 is on the order of $0.37 \%$. This effect increases for smaller diameters and larger variances. For calibration purposes, this effect can be neglected due to the small variance of the peaks $(\sigma \cong 2.0 \mu \mathrm{m})$ and the relatively large particle diameters (400 to $800 \mu \mathrm{m})$.

\section{CALIBRATION ACCURACY}

In calibrating the analyzer, the uncertainty in the sizes of the steel microspheres and their peak channels gives rise to an error term to be included with the particle sample's standard deviation. Once the mean channel of a distribution $(y)$ has been determined, the mean cross-sectional area is determined according to the relationship:

$$
\bar{a}=\frac{1}{m}(\bar{y}-b) .
$$

The particle sample diameter $d$ is then calculated from $\bar{a}$. The variation in $\bar{a}$ due to the deviation in $m, \bar{y}$, and $b$ is given by:

$$
\sigma_{\bar{a}}^{2}=\bar{a}^{2}\left[\frac{\sigma_{\bar{y}}^{2}+\sigma_{b}^{2}}{(\bar{y}-b)^{2}}+\frac{\sigma_{m}^{2}}{m^{2}}\right] .
$$

While $\sigma_{\bar{y}}$ can be calculated directly from the spectrum, the variation in $m$ and $b$ must be calculated beforehand.

The slope is calculated according to the least squares fit equation:

$$
m=\frac{n \sum_{i=1}^{n} a_{i} y_{i}-\sum_{i=1}^{n} a_{i} \sum_{i=1}^{n} y_{i}}{n \sum_{i=1}^{n} a_{i}^{2}-\left(\sum_{i=1}^{n} a_{i}\right)^{2}}
$$


for a calibration set consisting of $n$ sizes of steel microspheres where $a_{i}$ is the cross-sectional area of the $i$ th size of steel microspheres and $y_{i}$ is its peak channel as recorded by the analyzer. The variance in $m$ will then be the sum of the weighted variances in the $a_{i}$ and $y_{i}$ measurements. Accordingly,

$$
\sigma_{m}{ }^{2}=\sum_{i=1}^{n}\left(\frac{\partial m}{\partial a_{i}}\right) \sigma_{a_{i}}{ }^{2}+\sum_{i=1}^{n}\left(\frac{\partial m}{\partial y_{i}}\right)^{2} \sigma_{y_{i}}^{2}=\sigma_{m}{ }^{2}(a)+\sigma_{m}{ }^{2}(y)
$$

The variance in $a_{i}$ corresponds to the error in measuring the diameters $x_{i}$ of the calibration microspheres. The variance in the peak channels $y_{i}$ can be calculated directly from the channel/count distribution.

Evaluatıng the partıal derivatıves we get:

$$
\sigma_{m}^{2}(a)=\frac{\sum_{i=1}^{n}\left\{2\left(n u_{j}=\sum_{i=1}^{n} u_{i}\right)\left(n \sum_{i=1}^{n} u_{i} y_{i}-\sum_{i=1}^{n} u_{i} \sum_{i=1}^{n} y_{i}\right)=\left(n j_{j}-\sum_{i=1}^{n} y_{i}\right)\left[n \sum_{i=1}^{n} u_{i}^{?}-\left(\sum_{i=1}^{n} u_{i}\right)^{2}\right]\right\}^{2} v_{a_{j}}^{2}}{\left[n \sum_{i=1}^{n} u_{i}^{2}-\left(\sum_{i=1}^{n} a_{i}\right)^{2}\right]^{4}}
$$

and

$$
\sigma_{m}^{2}(y)=\frac{\left[\sum_{i=1}^{n}\left(n a_{j}-\sum_{i=1}^{n} a_{l}\right)^{2} \sigma_{y \prime}^{2}\right]}{\left[n \sum_{i=1}^{n} a_{i}^{2} \cdot\left(\sum_{i=1}^{n} a_{i}\right)^{2}\right]^{2}}
$$

Once we have calculated $m$ we can obtain $b$ from the relation:

$$
b=y^{*}-i m u^{*},
$$

where

$$
y^{*}=\frac{1}{n} \sum_{i=1}^{n} y_{i}
$$

and

$$
a^{*}=\frac{1}{n} \sum_{i=1}^{n} a_{i}
$$


The variance in $b$ is then given by:

$$
\sigma_{b}^{2}=\sigma_{y *}^{2}+m^{2} \sigma_{a}^{2}+a^{* 2} \sigma_{m}^{2}
$$

where

$$
\sigma_{y *}^{2}=\frac{1}{n^{2}} \sum_{i=1}^{n} \sigma_{y_{i}}{ }^{2}
$$

and

$$
\sigma_{a^{*}}^{2}=\frac{1}{n^{2}} \sum_{i=1}^{n} a_{i}^{2}
$$

The variation can then be rewritten as:

$$
\sigma_{b}^{2}=\frac{1}{n^{2}}\left[\sum_{i=1}^{n}\left(\sigma_{y_{i}}{ }^{2}+m^{2} \sigma_{a_{i}}^{2}\right)+\left(\sum_{i=1}^{n} a_{i}\right)^{2} \sigma_{m}^{2}\right]
$$

Table 2 lists the results of light-wave micrometer measurements of the steel microsphere calibration sample. One percent of the microspheres were sized in this manner. Traceability to the National Bureau of Standards was established through ORNL secondary standards set no. UCC 72, serial no. 7.1669 CRAA5, calibrated February 25, 1976.

The analyzer's measurement of the peak channels for the calibration sample yields standard deviations ranging from 1.00 to 1.30 channels. Using these values for the $\sigma_{y_{i}}$ together with the $\sigma_{a_{i}}$ from Table 2, the uncertainty in the mean diameter at the $95 \%$ confidence level due to calibration error was calculated to be less than $\pm 0.30 \mu \mathrm{m}$.

The calculated curve fits the particle size within the total $95 \%$ confidence interval for the larger-sized particles. At the low end, the calculated value is still within 0.3 or $0.4 \mu \mathrm{m}$, although the fit to the curve is not as good. R-square values of 0.9999 are typical.

Since we are dealing with coated particle samples containing several thousand particles and standard deviations ranging from 20 to $40 \mu \mathrm{m}$, the error introduced in calibration is minimal, as is the effect of variance from the curve for smaller-sized particles.

Table 2. Measurement of steel microsphere calibration sample by light-wave micrometer

\begin{tabular}{ccc}
\hline $\begin{array}{c}\text { Mean diameter } \\
(\mu \mathrm{m})\end{array}$ & $\begin{array}{c}\text { Standard deviation } \\
(\mu \mathrm{m})\end{array}$ & $\begin{array}{c}95 \% \text { confidence } \\
\text { interval } \\
(\mu \mathrm{m})\end{array}$ \\
\hline 379.16 & 0.21 & 0.11 \\
506.15 & 0.34 & 0.18 \\
633.10 & 0.17 & 0.09 \\
791.99 & 0.17 & 0.09 \\
\hline
\end{tabular}




\section{DATA ACQUISITION}

As discussed earlier, the current output of the photodiode is fed to an amplifier/converter which converts current drops into positive voltage pulses which are digitized by an analog-to-digital converter (ADC) and stored in a multi-channel analyzer. The multi-channel pulse height analyzer (Nuclear Data 2400 model) has a 100-Mhz ADC with a conversion gain selectable from 256 to 8192 channels for an $8-\mathrm{V}$ full-scale signal. The analyzer typically operates with a conversion gain of 4096, providing a scale of 0 to 4 $\mathrm{V}$ which may be selected and expanded for viewing. The memory section is capable of recording 1024 channels with a full-scale zero suppression, allowing the recording of any 1024-channel segment of the output even at the highest conversion gain. It also has the capability of being broken down into as many as four equal portions of 256 channels each, with the ability to accumulate an individual spectrum in each portiun. Control over these functions provides great flexibility in accumulating spectra of the steel microspheres, calibration disk, and fuel particle samples.

Figure 10 is a photograph of the particle-size analyzer set to recirculate a single particle or several particles of different sizes. At the upper right are the pressure gauges which indicate singularizer drum vacuun, bluw-off jet pressure, and transfer vacuum. Directly below these is located the cyclone receiver, which receives particles from the detection module through the polyethylene tubing entering from the right. Attached to the bottom of the receiver is the rotating vacuum lock which collects the disentrained particle and drops it into the singularizer hopper. Located under the singularizer drum, the detcction

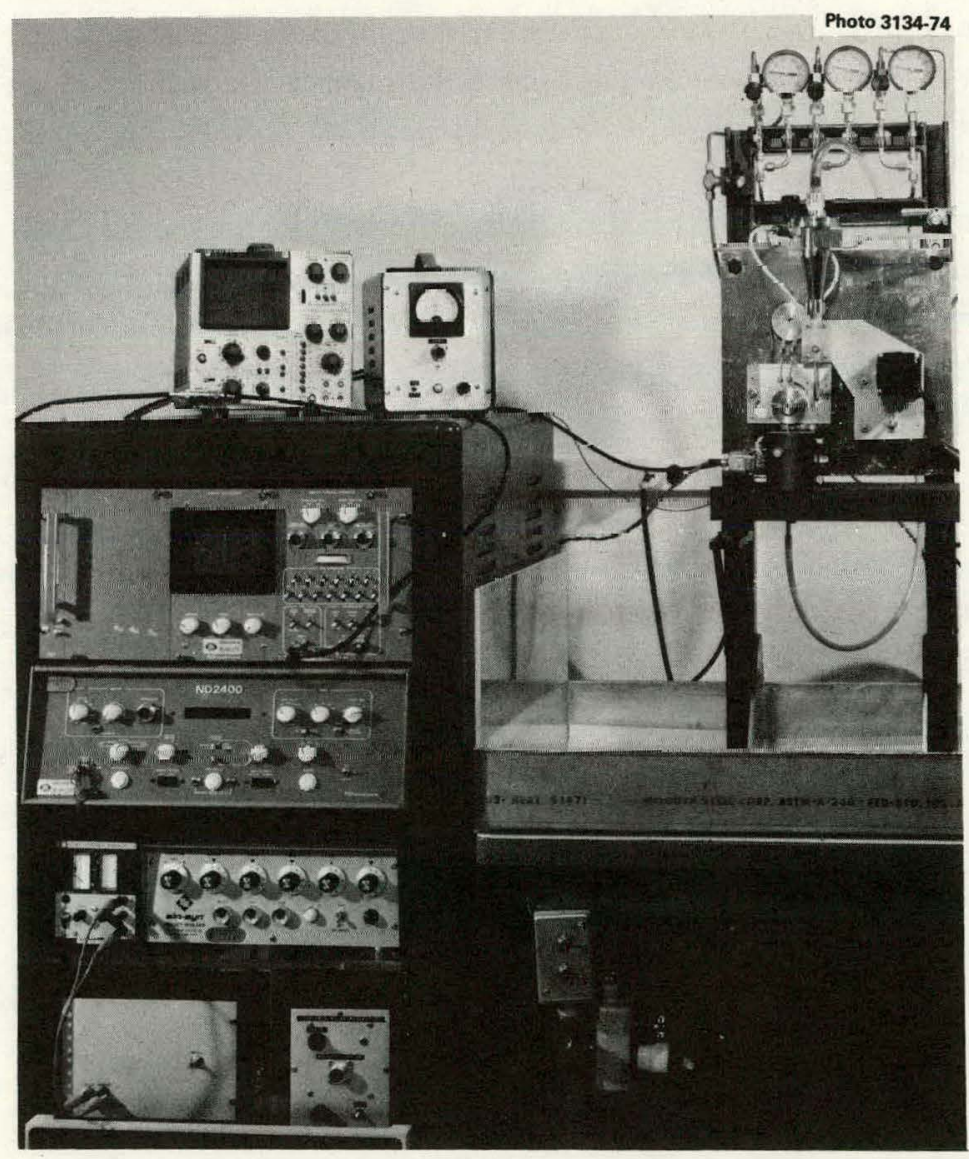

Fig. 10. Particle-size analyzer with single particle repeater and data collection system, excluding computer and teletype. 
module houses the light source, sensor, and calibration disk. On the left are an oscilloscope and the amplifier/converter on top of the rack. Below these are the multi-channel pulse height analyzer, indexer for the singularizer drum, and the regulated power supply and controls for the calibration disk.

After a spectrum has been accumulated, the data is transferred automatically from the analyzer to the computer system, a PDP-8/E computer modified by the addition of a $1 \mathrm{k}$ read-only memory, the expansion of the original $4 \mathrm{k}$ core to $8 \mathrm{k}$, and the addition of a Sykes Compucorder 100 magnetic tape cassette unit to permit the rapid exchange of programs. The tape cassette allows the computer to be used for several instruments in addition to the particle-size analyzer. The computer is programmed in FOCAL, an interactive language of sufficient simplicity to permit the rapid preparation and modification of programs for processing the data.

\section{SUMMARY}

To briefly summarize the operation of the particle-size analyzer, fuel particles ranging in diameter from 300 to $1000 \mu \mathrm{m}$ are individually measured at rates up to 2000 per minute and collected undamaged for further analysis. Samples containing 5000 to 10,000 particles can be measured and weighed within 10 to 15 min, providing information on the particle-size distribution, number of particles, and sample weight. From this information can be calculated a mean particle diameter, the standard deviation of the distribution, and mean particle weight, volume, and density. By sampling both before and after the application of a coating layer, we can determine the mean thickness, volume, and density of that layer. This information can all be obtained within a turnaround time acceptable for altering or modifying the coating process to compensate for changing conditions.

Because of its size and the small number of moving parts, the particle-size analyzer is readily adaptable to remote operation and glove box maintenance. Only the singularizer, hopper, detection module, and cyclone receiver need to be located within the enclosure, occupying a space of approximately $1 \mathrm{ft}^{3}$. All of the control mechanisms can be located at the operator's station, together with the computational. equipment and data printout. These features make the particle-size analyzer ideal for measuring spherical or near-spherical radioactive or toxic particles in a remote facility.

\section{ACKNOWLEDGMENTS}

The authors wish to thank L. J. Turner for his perseverance and contributions to the development of the particle-size analyzer. L. H. Thacker and W. R. Miller of the Instrumentation and Controls Division are to be commended for their development of the state-of-the-art amplifier/converter which is the heart of the particle-size analyzer's electronics. The comments of R. A. Bradley and A. J. Moorehead in editing this report are greatly appreciated. We would also like to thank Elizabeth Giddings for editing the manuscript and the Technical Publications personnel for preparing the document for reproduction.

The authors would also like to extend their appreciation to the International Atomic Energy Agency for choosing an excellent drawing of the particle-size analyzer made by H. R. Livesey for the cover of their proceedings on nuclear fuel quality assurance, ${ }^{12}$ the drawing being a small portion of a fine presentation by W. J. Lackey of a paper authored by W. H. Pechin, W. J. Lackey, J. D. Sease, and W. P. Eatherly.

12. Nuclear Fuel Quality Assurunce: Proceedings of a Scminar, Oslo, 24-27 May 1976, International Atomic Energy Agency, Vienna, 1976. 
THIS PAGE

\section{WAS INTENTIONALLY LEFT BLANK}


1-2. Central Research Library

3. Document Reference Section

4-12. Laboratory Records Department

13. Laboratory Records, ORNL RC

14. ORNL Patent Office

15. R. K. Adams

16. P. Angelini

17. S. P. Baker

18. B. O. Barringer

19. B. J. Baxter

20. R. J. Beaver

21. R. Blumberg

22. B. J. Bolfing

23. R. J. Braatz

24. R. A. Bradley

25. A. J. Caputo

26. J. A. Carpenter

27. H..E. Cuchran

28. D. A. Costanzo

29. F. C. Davis

30. J. P. Drago

31. R. G. Donnelly

32. D. A. Dyslin

33. D. E. Ferguson

34. P. A. Haas

35. C. C. Haws

36. F. E. Harrington

37. J. L. Heck

38. L. C. Hensley

39. R. E. Helms

40-42. M. R. Hill

43. R. M. Hill

44. D. R. Johnson

45. M. J. Kania

46-48. P. R. Kasten

49-54. W. J. Lackey
55. K. H. Lin

56. H. R. Livesey

57-58. A. L. Lotts

59-63. J. E. Mack

64. M: M. Martin

65. S. R. McNeany

66. K. J. Notz

67. A. R. Olsen

68. R. M. Peach

69-73. W. H. Pechin

74. M. K. Preston

75. R. H. Rainey

76. D. P. Reid

77. J. E. Rushton

78. T. F. Scanlan

79. D. C. Scott

80. J. H. Shaffer

81. R. L. Shepard

82. D. P. Stinton

83. R. R. Suchomel

84. V. J. Tennery

85. L. H. Thacker

86. S. M. Tiegs

87. T. N. Tiegs

88. D. B. Trauger

89. G. C. Wei

90. J. R. Weir

91. M. G. Willey

92. J.W. Woods

93. R. W. Balluffi (consultant)

94. P. M. Brister (consultant).

95. W. R. Hibbard, Jr. (consultant)

96. Hayne Palmour III (consultant)

97. N. E. Promisel (consultant)

98. D. F. Stein (consultant) 
EXTERNAL DISTRIBUTION

99-100. ERDA DIVISION OF REACTOR NUCLEAR RESEARCH AND APPLICATIONS, Washington, DC 20545

Director

101. ERDA IDAHO OPERATIONS OFFICE, P.O. Box 2108, Idaho Falls, ID 83401

Barry Smith

102. ERDA OFFICE OF PROGRAM MANAGEMENT, RESEARCH AND SPACE PROGRAMS, P.O. Box 81325, San Diego, CA 92138

J. B. Radcliffe

103. ERDA SAN FRANCISCO OPERATIONS OFFICE, 1333 Broadway, Wells Fargo Building, Oakland, CA 94612

Manager

104-107. ERDA DIVISION OF WASTE MANAGEMENT, PRODUCTION AND PROCESSING, Washington, DC 20545

Acting Assistant Director for Reprocessing

Chief, Technology Branch

Chief, Projects Branch

Chief, Industrial Programs Branch

108-110. ERDA OAK RIDGE OPERATIONS OFFICE, P.O. Box E, Oak Ridge, TN 37830

Director, Research and Technical Support Division

Director, Reactor Division

F. E. Dearing, Reactor Division

111-291. ERDA TECHNICAL INFORMATION CENTER, P.O. Box 62, Oak Ridge, TN 37830

For distribution as sliuwil in TID-4500 Distribution Category,

UC-77 (Gas-Cooled Reactor Technology)

292-299. ERDA Exchange Agreements with Germany and Diazon Project 